\title{
$\beta$-Carboline Photosensitizers. 3. Studies on Ground and Excited State Partitioning in AOT/Water/Cyclohexane Microemulsions
}

\author{
A. P. Varela, ${ }^{\dagger}$ M. da G. Miguel, ${ }^{\dagger}$ A. L. Maçanita, ${ }^{\ddagger}$ Hugh D. Burrows, ${ }^{*, \dagger}$ and Ralph S. Becker ${ }^{*}$ \\ Departamento de Química, Universidade de Coimbra, 3049 Coimbra, Portugal, and Departamento de Química \\ de I.S.T., Instituto de Tecnologia Química e Biologia, Oeiras, Portugal
}

Received: July 5, $1995^{\otimes}$

\begin{abstract}
The photophysical behavior of the $\beta$-carbolines norharmane, harmane, and harmine has been studied in waterin-oil (w/o) microemulsions in AOT/cyclohexane. With pure solvents, solubility and partitioning studies indicate that these molecules dissolve preferentially in the organic phase but that their solubility in the aqueous phase increases upon decreasing $\mathrm{pH}$ as a consequence of protonation. However, in w/o microemulsions these molecules appear to be located predominantly at the surfactant/water interface. Again, decreasing pH increases partitioning into the water region. From absorption and fluorescence spectral studies with the microemulsion system, differences are observed in the predominant species at any " $\mathrm{pH}$ " compared with that in pure water. From analysis of fluorescence decays, four kinetically distinguishable species have been observed in the excited state, namely, neutral species in cyclohexane, neutral species in the microemulsion droplets, cation, and zwitterion. For harmine, the effect of water/surfactant ratio $\left(w_{0}\right)$ on the photophysical behavior and distribution of these species was studied. Partitioning was observed between aqueous and organic subphases. A study has been carried out on the effect of $\mathrm{pH}$ on these processes. In agreement with other studies on " $\mathrm{pH}$ " in microemulsions, the cation is observed up to apparent $\mathrm{pH}$ values much higher than those for pure aqueous solutions. The results are interpreted in terms of the compartmentalization of the hydroxide ions between the water pools. Effects of changing $w_{0}$ on the decay of the various species are interpreted in terms of "quenching" of the neutral species in the cyclohexane subphase by its trapping within the microemulsion droplets. A kinetic model for this is presented. The effect of changing the polarity (by addition of methanol) upon the partitioning behavior has been studied, and it is shown that addition of methanol favors partitioning into the organic phase.
\end{abstract}

\section{Introduction}

The $\beta$-carboline alkaloids are a widely distributed group of naturally occurring compounds, linked by a common tricyclic system having adjacent indole and pyridine rings. ${ }^{1}$ These show photosensitizing activity toward a variety of systems, including bacteria, fungi, viruses, insects, etc. ${ }^{2-6}$ In addition, it is suggested that these compounds are formed as photoproducts from tryptophan in human lenses. ${ }^{7-9}$ A large number of photophysical studies have been carried out on these compounds, ${ }^{10-20}$ stimulated by both their application in areas, such as their use as fluorescence standards, ${ }^{10,11}$ and their photobiological relevance.

Particular interest has been shown in the acid-base behavior of the $\beta$-carbolines. Because of charge-density differences in the ground and excited states of the pyrrole and pyridine rings, interesting tautomeric behavior is observed, with neutral forms in the ground state being replaced by zwitterions and cations in the excited state in polar solvents. ${ }^{12.13,19}$

It is suggested that important factors in the phototoxicity of these compounds include their localization in relation to the target molecules ${ }^{6}$ and their diffusion across membranes. ${ }^{3}$ In spite of the importance of their solubility behavior in these areas, it is surprising that our knowledge of the partitioning of the various forms between water and nonpolar phases is very limited. Qualitative measurements have been made on the polarity of the molecules in the ground state using chromatog-

\footnotetext{
* To whom correspondence should be addressed.

† Universidade de Coimbra.

* Instituto de Tecnologia Química e Biológica.

8 Abstract published in Advance ACS Abstracts, September 15, 1995.
}

raphy, $6,21,22$ and distribution coefficients between 1-octanol and water have been reported for alkaline solutions. ${ }^{22}$

In an earlier report, ${ }^{18}$ the photophysics of the excited singlet states of the $\beta$-carbolines norharmane, harmane, harmine, and, to a lesser extent, harmaline were considered in the solvents benzene and methanol, and both experimental measurements and theoretical calculations were used to assign the various species produced in the excited state. In nonpolar solvents, only a neutral species $\left(\mathrm{N}^{*}\right)$ is observed upon excitation. However, in the protic solvent methanol, cationic $\left(\mathrm{C}^{*}\right)$ and zwitterionic $\left(\mathrm{Z}^{*}\right)$ species are also formed, in the complex equilibria, shown schematically:

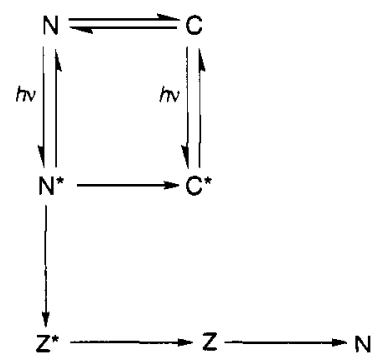

Note that in the absence of a strong base (such as hydroxide) the interconversion of $\mathrm{N}^{*}$ to $\mathrm{C}^{*}$ or $\mathrm{Z}^{*}$ is, effectively, irreversible. We extend this study to the photophysical behavior of $\beta$-carbolines in water-in-oil microemulsions formed by the anionic surfactant Aerosol-OT (sodium bis(2-ethylhexyl) sulfosuccinate, abbreviated AOT). The microemulsion droplets in these have a water pool of a few nanometers diameter surrounded by a surfactant layer and a continuous hydrocarbon phase. Because 


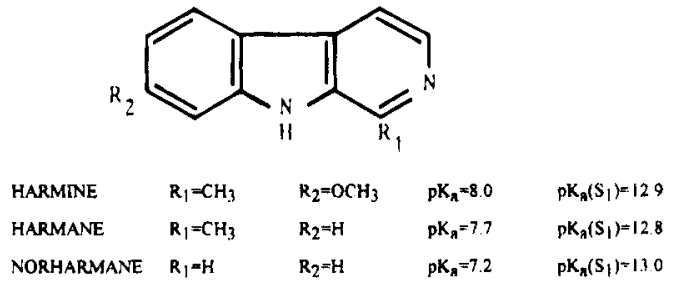

Figure 1. Structures and ground and excited state $\mathrm{p} K_{\mathrm{a}}$ values (from ref 15 ) for norharmane (1), harmane (2), and harmine (3).

of changes in the polarity of the $\beta$-carbolines upon excitation, it is anticipated that they can provide both dynamic and equilibrium information upon solute distribution in microemulsion systems. In addition to their relevance to our understanding of the behavior of microemulsions, these are expected to mimic certain facets of the behavior of $\beta$-carbolines in biological systems.

\section{Experimental Section}

Norharmane (1), harmane (2), and harmine (3) were used as purchased (Aldrich). The structures of these molecules and their ground and excited state $\mathrm{p} K_{\mathrm{a}}$ 's are given in Figure 1. Benzene, methanol (Merck, P.A., Uvasol), 1-octanol (Merck, P.A.), and cyclohexane (Merck, P.A., Uvasol) were used without further purification. For some solutions, methanol was dried by distillation over magnesium and chromatographed on an $\mathrm{Al}_{2} \mathrm{O}_{3}$ column. ${ }^{23}$ The surfactant AOT, $\mathrm{C}_{20} \mathrm{H}_{37} \mathrm{O}_{7} \mathrm{SNa}$, from Sigma, was dissolved in methanol and filtered with alumina, and the solvent was evaporated (purification procedure adapted from ref 24). The aqueous solutions of $\beta$-carbolines were prepared with bidistilled water by setting the concentration at $\sim 10^{-5} \mathrm{M}$, and the $\mathrm{pH}$ was adjusted with $\mathrm{NaOH}$ or $\mathrm{HCl}$ aqueous solutions. Microemulsion solutions were prepared with an AOT solution $(0.1 \mathrm{M})$ in cyclohexane, to which different amounts of water were added and vortexed, for molar ratios, $w_{0}=\left[\mathrm{H}_{2} \mathrm{O}\right] /[\mathrm{AOT}]$, varying from 2.5 to 20 , with $\mathrm{pH}$ before mixing adjusted to be in the range from 2.0 to 14.0 . For all $w_{0}$ values, phase separation was observed, at room temperature, for $\mathrm{pH}$ values lower than 2.0 and $>12.5$; as previously reported, ${ }^{25}$ phase separation was also observed for $w_{0}=20$ at $20{ }^{\circ} \mathrm{C}$.

The solubility of norharmane, harmane, and harmine was measured in water at $20^{\circ} \mathrm{C}$, at $\mathrm{pH} 7$ and 13 , using the absorbance at the maxima in the absorption spectra of saturated solutions and the respective molar extinction coefficients. At lower $\mathrm{pH}(\mathrm{pH} 2)$, where the cationic form is the predominant species, all the compounds present a very high solubility, and it was not possible to obtain data with this technique.

The partitioning of norharmane, harmane, and harmine between water and a hydrophobic phase was studied by the estimation of their partition coefficients, $P$ (as its logarithm (log $P$ )) between 1-octanol and water. This corresponds to their relative concentrations (weight per unit volume) in the two phases. ${ }^{26}$ This was carried out at $20^{\circ} \mathrm{C}$, for aqueous solutions of $\mathrm{pH} 7$ and $\mathrm{pH} 13$, and for 1-octanol solutions of concentrations $2.78 \times 10^{-4}, 2.09 \times 10^{-4}$, and $1.3 \times 10^{-4} \mathrm{M}$ for norharmane, harmane, and harmine, respectively. The solutions were thermostated before and after mixing and left $48 \mathrm{~h}$ for stabilization. The partition coefficients of the compounds between the organic and aqueous phases were obtained through their initial concentrations, absorption spectra, and molar extinction coefficients in the two phases [norharmane: $\log \epsilon_{301 \mathrm{~nm}}\left(\mathrm{H}_{2} \mathrm{O}\right) 4.03, \log$ $\epsilon_{282 \mathrm{~nm}}$ (octanol) 4.07; harmane: $\log \epsilon_{299 \mathrm{~nm}}\left(\mathrm{H}_{2} \mathrm{O}\right) 4.08$, log $\epsilon_{286 \mathrm{~nm}}$ (octanol) 4.21; harmine: $\log \epsilon_{246 \mathrm{~nm}}\left(\mathrm{H}_{2} \mathrm{O}\right) 4.53, \log$ $\epsilon_{240 \mathrm{~nm}}$ (octanol) 4.67].
TABLE 1: Solubility $(s)$ and Partition Coefficient $(P)$ Values of the $\beta$-Carbolines Norharmane, Harmane, and Harmine as a Function of $\mathrm{pH}$ and Temperature $\left(T=20^{\circ} \mathrm{C}\right)$

\begin{tabular}{lcccc}
\hline compound & $\begin{array}{c}s / \mathrm{M} \\
(\mathrm{pH}=7)\end{array}$ & $\begin{array}{c}s / \mathrm{M} \\
(\mathrm{pH}=13)\end{array}$ & $\begin{array}{c}\log P \\
(\mathrm{pH}=5.5)\end{array}$ & $\begin{array}{c}\log P^{a} \\
(\mathrm{pH}=13)\end{array}$ \\
\hline norharmane & $1.86 \times 10^{-4}$ & $1.81 \times 10^{-4}$ & $0.82 \pm 0.04$ & 3.17 \\
harmane & $1.61 \times 10^{-4}$ & $7.86 \times 10^{-5}$ & $0.70 \pm 0.05$ & 3.50 \\
harmine & $3.31 \times 10^{-5}$ & $2.08 \times 10^{-5}$ & $0.90 \pm 0.07$ & 3.56 \\
\multicolumn{2}{c}{${ }^{a}$ From ref 22.} & & &
\end{tabular}

Fluorescence decays were obtained using the time-correlated single-photon-counting technique as previously described..$^{27,28}$ The excitation wavelength was normally $337 \mathrm{~nm}$. At this wavelength both the neutral and cationic species are excited. In one experiment, excitation was at $380 \mathrm{~nm}$, where only the cation $\left(\mathrm{C}^{*}\right)$ absorbs. The decay of this species under these conditions was identical to that observed with $337 \mathrm{~nm}$ excitation. Alternate measurements ( $10^{3}$ counts at the maximum per cycle) of the pulse profile and the sample emission were continued until $3 \times 10^{4}$ counts at the maximum were reached. The photomultiplier wavelength shift was $1 \mathrm{ps} / \mathrm{nm}$ in the wavelength region of interest. The fluorescence decays were deconvoluted using a VAX 2000 computer using the modulation functions method with shift correction. ${ }^{29}$

\section{Results and Discussion}

Solubility and Partition Behavior. Solubilities in water and 1-octanol/water partition coefficients of the compounds norharmane, harmane, and harmine are presented in Table 1. For all the conditions harmine presents the lowest solubility in water, while norharmane is the most soluble. This agrees with previous partitioning studies on these systems. ${ }^{22}$ The results also confirm the higher solubility in neutral solutions $(\mathrm{pH} \mathrm{7)}$ in water compared with basic media ( $\mathrm{pH} 13)$ for all the compounds. This is associated with formation of the cation in the ground state, since the $\mathrm{p} K_{\mathrm{a}}$ values in all cases are in the region $7-8 .{ }^{15,19}$ With respect to partitioning of these compounds between organic and aqueous phases, literature values ${ }^{22}$ for all the compounds at $\mathrm{pH}$ 13 show very large partition coefficients, indicating only very minor quantities of the $\beta$-carbolines pass to the aqueous phase, the rest being either in 1-octanol or at the interface. At $\mathrm{pH}$ 5.5 , the results indicate more partitioning of the carbolines into the aqueous phase (Table 1), supporting the conclusions from the solubility studies. It is reasonable to conclude that the main partitioning is between cation in water and neutral species in 1-octanol.

Absorption and Emission Spectral Studies in Microemulsions. The $\beta$-carbolines norharmane, harmane, and harmine have been examined regarding absorption, emission, and excitedstate equilibria in several classes of organic solvents. ${ }^{18}$ In hydrocarbon and nonprotic solvents, excitation results only in an excited-state neutral species. In neutral protic solvents (i.e., methanol), excitation of the neutral form results in multiple excited-state species - neutral, cation, and zwitterion-and emission. The excited cation and zwitterion are formed from the neutral species during the lifetime of its lowest $\left(\pi, \pi^{*}\right)$ singlet state. A kinetic model has been developed for the complex decays, and an analysis has been presented for neutral protic solvents ${ }^{18}$ and for aqueous solutions at different $\mathrm{pH}$ 's. ${ }^{30}$ When ground state cation is directly excited, absorption, emission, and kinetic decay data show that only a single excited-state species exists and emits, independent of the solvent. ${ }^{18}$

The absorption and fluorescence spectra of all the compounds were studied in w/o microemulsions, water/AOT/cyclohexane, for the water/surfactant molar ratio $\left(\left[\mathrm{H}_{2} \mathrm{O}\right] /[\mathrm{AOT}]\right) w_{0}=5$ at 

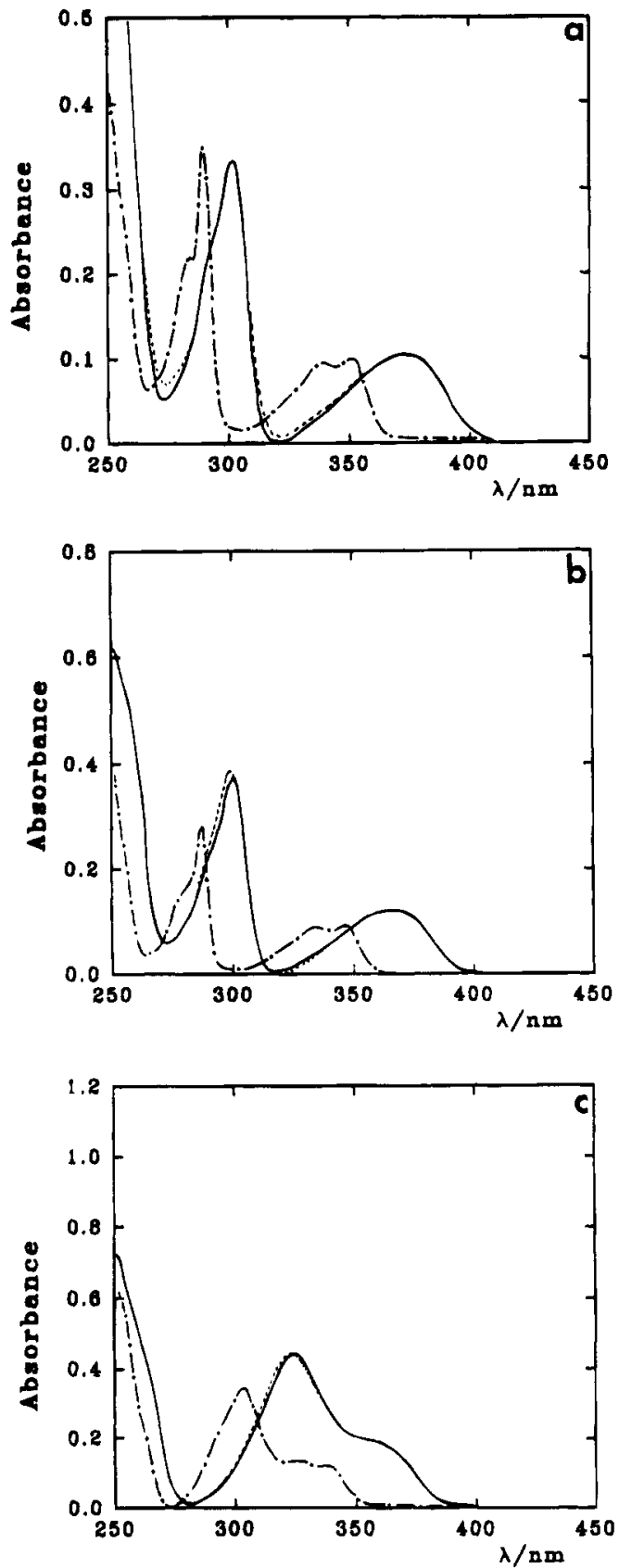

Figure 2. Absorption spectra of (a) norharmane, (b) harmane, and (c) harmine in AOT/water/cyclohexane microemulsions $\left(w_{0}=5\right)$ at $\mathrm{pH}$ $6.4(-), 12.4(--)$, and $12.8(-\cdot-)$.

different $\mathrm{pH}$ 's of added solution and are shown in Figures 2 and 3. Similar spectral behavior is observed for all of them, for $\mathrm{pH}$ values between 6.4 and 12.4 , where only the cationic species show absorption $(\lambda \sim 400-450 \mathrm{~nm})$. However, at $\mathrm{pH}$ 12.8 a different absorption band is seen, which is characteristic of the neutral form $(\lambda \sim 350-380 \mathrm{~nm})$. Comparable changes occur in the emission spectra. For example, in the case of harmine, from $\mathrm{pH} 10.3$ to $\mathrm{pH} 12.0$, a decrease can be seen for the emission of the cationic species $(\lambda=403 \mathrm{~nm})$, and a corresponding increase is observed for the emission of the neutral form $(\lambda=365 \mathrm{~nm})$. For harmane and norharmane similar behavior is observed in the emission for the neutral form at $\lambda=361 \mathrm{~nm}, \mathrm{pH} 12.5$, and at $\lambda=365 \mathrm{~nm}, \mathrm{pH} 12.3$, respectively. Note that for norharmane, at $\mathrm{pH} 12.3$, the emission spectrum is very similar to that observed in water with respect to the contribution of the $\mathrm{N}^{*}$ and $\mathrm{C}^{*}$ species. This can be related to the higher solubility of this compound in water, compared with the other carbolines.
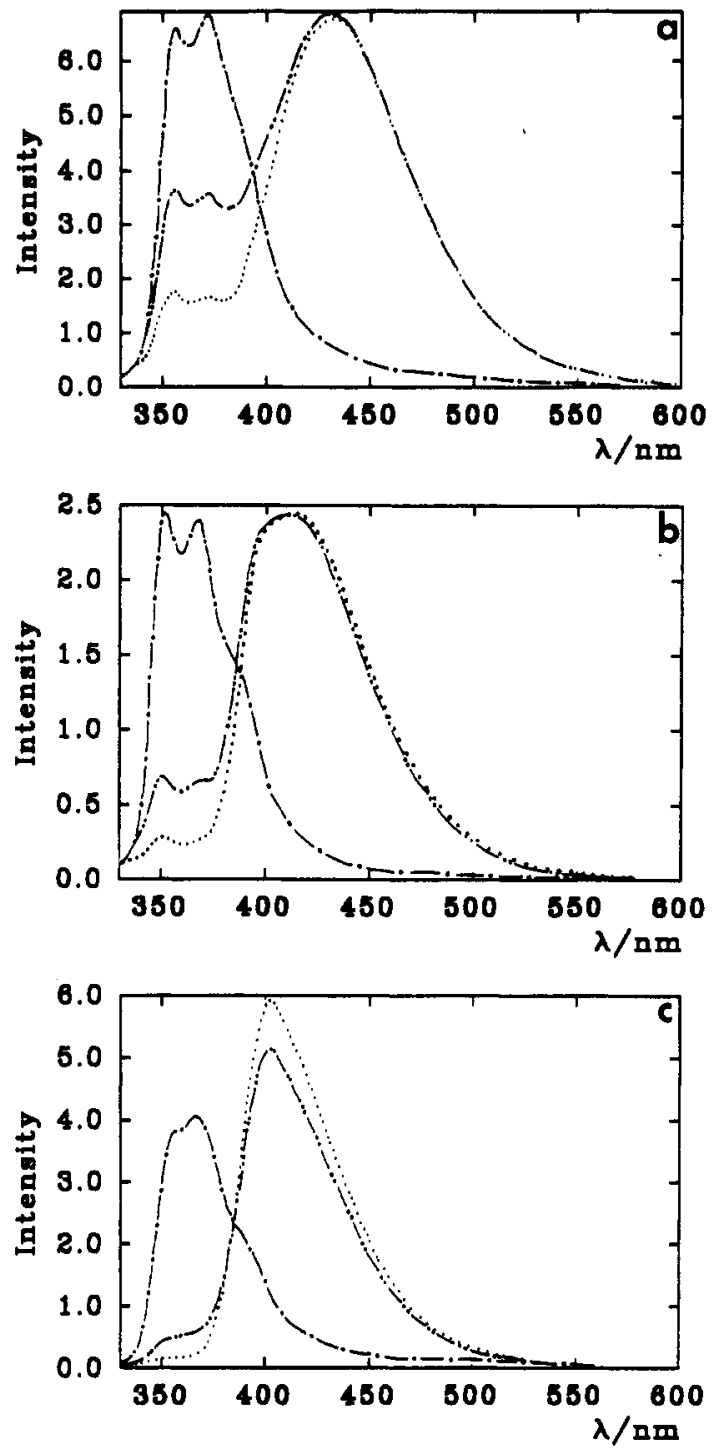

Figure 3. Fluorescence spectra of $\beta$-carbolines in AOT/water/ cyclohexane microemulsions $\left(w_{0}=5\right)$ : (a) norharmane at $\mathrm{pH} 10.5(\cdots)$, $12.3(-\cdots-)$, and $13.0(-\cdot-)$; (b) harmane at $\mathrm{pH} 10.3(\cdots), 12.5$ $(-\cdot-)$, and $13.2(-\cdot-)$; (c) harmine at $\mathrm{pH} 10.3(\cdots), 12.0(-\cdots-)$, and $12.8(-\cdot-)$.

Harmine was also studied over the same $\mathrm{pH}$ range at $w_{0}=$ 12.5 , where better definition of the species is observed. Absorption and emission spectra are shown in Figures 4 and 5 , respectively. In both cases, well-defined isosbestic points are observed, showing clean interconversion of $\mathrm{C}^{*}$ to $\mathrm{N}^{*}$ upon increasing $\mathrm{pH}$. However, as will be discussed with the fluorescence decays, because of the compartmentalization of the hydroxide ions between the microemulsion droplets, care needs to be taken in the interpretation of $\mathrm{pH}$ in these systems.

Effect of Water/Surfactant Mole Ratio on Photophysical Behavior. Harmine was chosen as a representative $\beta$-carboline to study their spectral behavior and kinetic decays as a function of different water/surfactant ratios $\left(w_{0}\right)$ and of $\mathrm{pH}$. Absorption and fluorescence spectra of harmine are given in Figure 6 in microemulsions of different $w_{0}$ ratios. A change in the relative intensities of the neutral and cationic forms can be seen for different $w_{0}$ values. At $w_{0}=2.5$ the contributions of both species are approximately equal. However, a significant decrease in the contribution of the neutral form is observed with increasing $w_{0}$. This is followed by a corresponding increase in the absorbance of the cationic species (Figure 6a). The same is clearly observed in the emission spectra at 367 and $410 \mathrm{~nm}$ for the neutral and cation, respectively (Figure 6b). The 


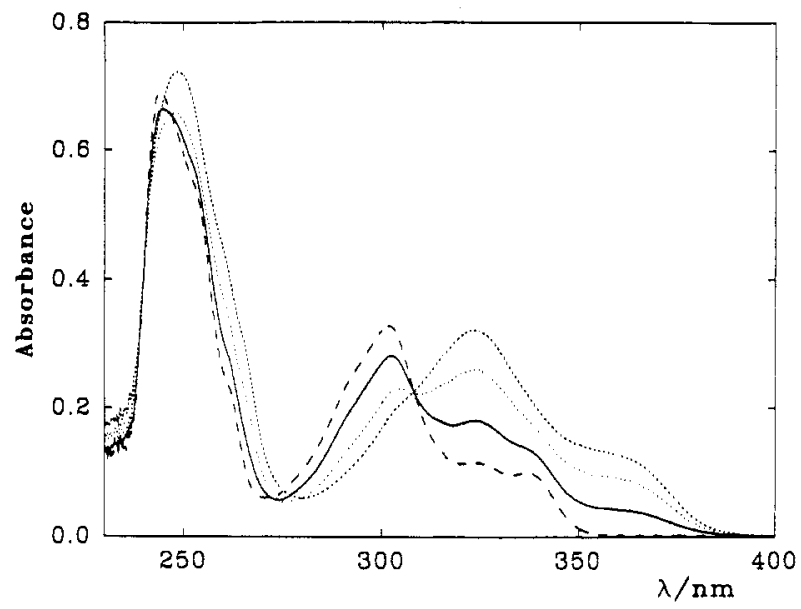

Figure 4. Absorption spectra of harmine in AOT/cyclohexane microemulsions $\left(w_{0}=12.5\right)$ at $\mathrm{pH} 5.5(--), 11.0(\cdots), 11.5(-)$, and 12.4 $(--)$.

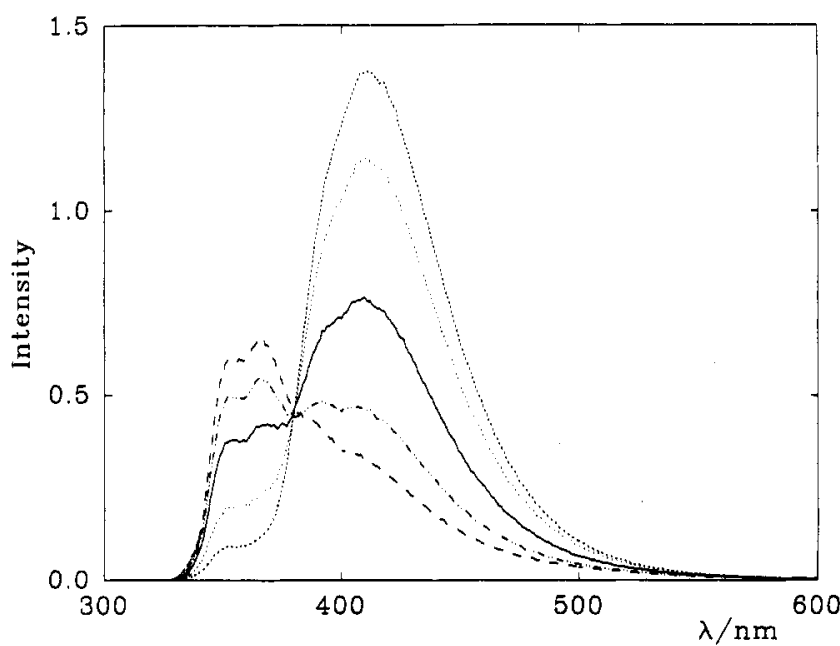

Figure 5. Emission spectra of harmine in AOT/cyclohexane microemulsions $\left(w_{0}=12.5\right)$ at $\mathrm{pH} 5.5(--), 11.0(\cdots), 11.5(-), 12.0$ $(-\cdot-)$, and $12.4(--)$.

excitation spectra also confirm these observations. These results are in agreement with the effect of increasing volume fraction of microemulsion droplets on the predicted partitioning of harmine (and the other $\beta$-carbolines studied) between the organic and microemulsion droplet subphases. The kinetic behavior of harmine in the excited state was studied in the microemulsion system. The decay of its emission was studied following excitation of its solution $\left(\lambda=337 \mathrm{~nm},[\mathrm{AOT}]=0.1 \mathrm{M}, w_{0}=\right.$ 12.5 ) at various $\mathrm{pH}$ values. Emission was studied at the wavelengths 350,410 , and $500 \mathrm{~nm}$, where the dominant excited species are $\mathbf{N}^{*}, \mathrm{C}^{*}$, and $\mathrm{Z}^{*}$, respectively. Data were analysed in terms of mono-, bi-, and triexponential decays to get the best possible statistical fit and are presented in Table 2. From the analysis, there appear to be four kinetically distinguishable components, whose lifetimes are independent of observation wavelength. These are assigned, on the basis of spectral studies and lifetimes in pure solvents, ${ }^{18,3^{\circ}}$ to the neutral species in the microemulsion droplets $\left(\tau_{1}\right)$, neutral species in cyclohexane $\left(\tau_{2}\right)$, cation $\left(\tau_{3}\right)$, and zwitterion $\left(\tau_{4}\right)$. A number of facts become apparent from these results. First, these four species are observed over the whole $\mathrm{pH}$ range studied, showing that there must be partitioning in the ground and/or excited state between aqueous and organic phases of some of the species. Second, in agreement with the spectral data, the cation is observed up to apparent $\mathrm{pH}$ values considerably in excess of the $\mathrm{p} K_{\mathrm{a}}$ of $\mathrm{C}$ in aqueous solutions. Variations of indicator $\mathrm{p} K_{\mathrm{a}}$ (or of $\mathrm{pH}$ )
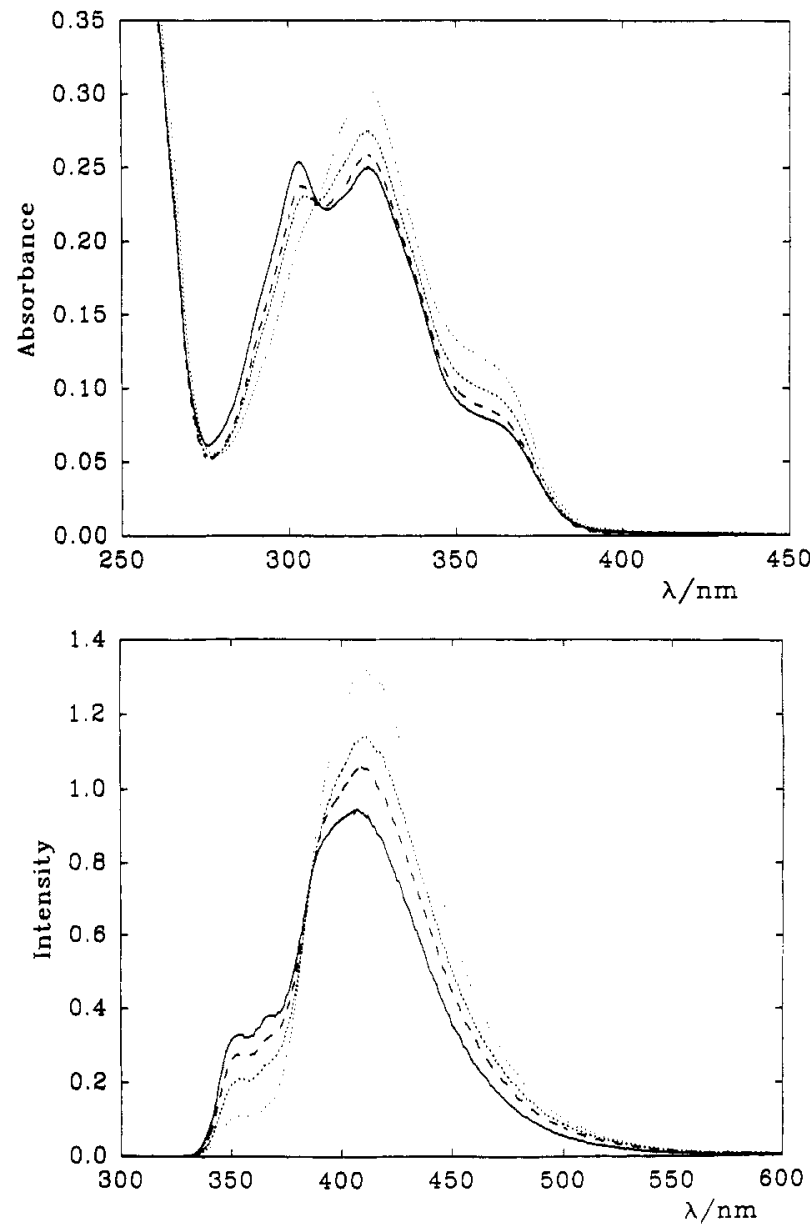

Figure 6. (a, top) Absorption and (b, bottom) emission spectra of harmine in AOT/cyclohexane microemulsions at $\mathrm{pH} 5.5$ and different $w_{0}$ values $2.5(-), 5(-), 7.5(--)$, and $10(\cdots)$.

TABLE 2: Fluorescence Decay Times $\left(\tau_{i}\right)$ and Preexponential Factors $\left(a_{i}\right)$ for Decay of Harmine Fluorescence in $\mathrm{AOT} / \mathrm{H}_{2} \mathrm{O} / \mathrm{Cyclohexane}$ Microemulsions $\left([\mathrm{AOT}]=0.1 \mathrm{M}, \omega_{0}=12.5\right)$ at $20^{\circ} \mathrm{C}$ as a Function of $\mathrm{pH}$

\begin{tabular}{ccccccccccc}
\hline $\mathrm{pH}$ & $\lambda_{\mathrm{em}} / \mathrm{nm}$ & $\tau_{1} / \mathrm{ns}$ & $\tau_{2} / \mathrm{ns}$ & $\tau_{3} / \mathrm{ns}$ & $\tau_{4} / \mathrm{ns}$ & $a_{1}$ & $a_{2}$ & $a_{3}$ & $a_{4}$ & $\chi^{2}$ \\
\hline 5.5 & 350 & 1.3 & 3.2 & 6.1 & & 0.18 & 0.75 & 0.06 & & 1.11 \\
& 410 & & & 6.0 & & & & 1.00 & & 1.08 \\
& 500 & 1.4 & & 6.1 & 22.0 & -0.21 & & 0.98 & 0.01 & 1.27 \\
11.0 & 350 & 1.8 & 3.1 & 6.1 & & 0.070 & 0.89 & 0.035 & & 1.08 \\
& 410 & 1.7 & & 6.0 & & -0.01 & & 1.00 & & 0.97 \\
& 500 & 1.5 & & 6.2 & 22.0 & -0.25 & & 0.98 & 0.02 & 1.06 \\
11.5 & 350 & 1.6 & 3.1 & 6.2 & & 0.084 & 0.90 & 0.019 & & 1.05 \\
& 410 & 1.6 & & 6.1 & & -0.09 & & 1.00 & & 0.88 \\
& 500 & 1.7 & & 6.2 & 20.0 & -0.35 & & 0.95 & 0.05 & 1.05 \\
12.0 & 350 & 2.2 & 3.6 & & & $a$ & $a$ & & & 1.08 \\
& 410 & 2.3 & & 6.0 & & -0.17 & & 1.00 & & 0.95 \\
& 500 & 2.2 & & 6.3 & 21.0 & -0.39 & & 0.94 & 0.06 & 1.03 \\
12.4 & 350 & & 3.2 & & & & 1.00 & & & 1.13 \\
& 410 & 2.5 & & 6.0 & & -0.41 & & 1.00 & & 1.05 \\
& 500 & 2.5 & & 6.2 & 20.0 & -0.53 & & 0.88 & 0.12 & 1.13
\end{tabular}

a The separation of the Preexponential factors was not possible, but $a_{1}+a_{2}=1.0$.

have previously been reported for microemulsion systems ${ }^{31}$ and have been associated with changes in the localization site. However, in the present system, using nonbuffered aqueous solution, the compartmentalization of hydroxide ions between the microemulsion droplets must also be considered. The statistical distribution of quencher molecules among micelles ${ }^{32,33}$ or microemulsion droplets ${ }^{34}$ has been treated in terms of a Poisson curve. If we assume that the water in the microemulsion droplets has a similar autoprotolysis constant to bulk water, then the distribution of hydroxide ions between the droplets can be 
TABLE 3: Calculated "Quenching" Rates for the Decay of Harmine Excited Neutral Species in Cyclohexane in AOT/ $\mathrm{H}_{2} \mathrm{O} /$ Cyclohexane $([\mathrm{AOT}]=0.1 \mathrm{M})$ Microemulsions at Different $\omega_{0}$ Values

\begin{tabular}{llcc}
\hline$\omega_{0}$ & $N^{a}$ & $r_{\mathrm{m}} / \mathrm{nm}^{b}$ & $\begin{array}{c}k_{\mathrm{q}} \times 10^{10} / \mathrm{dm}^{3} \\
\left(\text { mol of micelle) }{ }^{-1} \mathrm{~s}^{-1}\right.\end{array}$ \\
\hline 2.5 & $31.5^{c}$ & 1.64 & 0.48 \\
5 & 72 & 1.94 & 2.35 \\
7.5 & 104.5 & 2.24 & 6.31 \\
10 & 116 & 2.54 & 8.90 \\
12.5 & $145.5^{\text {c.d }}$ & 2.84 & 13.84 \\
15 & 175 & 3.14 & 16.64
\end{tabular}

${ }^{a}$ Aggregation number for microemulsions, using data from ref 42 . ${ }^{b}$ Microemulsion radius from ref $42 .{ }^{c}$ By interpolation. ${ }^{d}$ From ref 43 for microemulsions in decane.

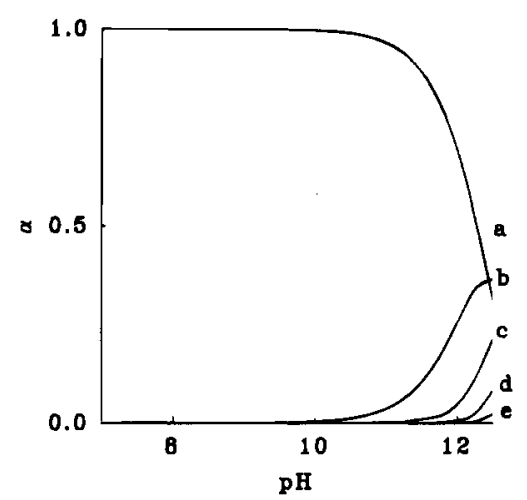

Figure 7. Poisson distribution of number of hydroxide ions per microemulsion droplet as a function of $\mathrm{pH}$ for the system AOT $(0.1$ M), water $\left(w_{0}=12.5\right)$, cyclohexane. (a) $i=0$, (b) $i=1$, (c) $i=2$, (d) $i=3$, (e) $i=4$.

treated in the same way. The fraction of microemulsion droplets (a) containing $i$ molecules of $\mathrm{OH}^{-}$is given by ${ }^{33}$

$$
\alpha=\left[\mathrm{M}_{i}\right] /[\mathrm{M}]=\overline{n_{\mathrm{OH}^{-}}}{ }^{i} \exp \left(-\overline{n_{\mathrm{OH}^{-}}}\right) / i !
$$

where $\left[\mathrm{M}_{i}\right]$ is the concentration of droplets containing $i$ molecules of hydroxide, $[\mathrm{M}]$ is the total concentration of droplets (given by $[\mathrm{AOT}] / N$, where $N$ is the aggregation number), and $\overline{n_{\mathrm{OH}^{-}}}$is the average number of $\mathrm{OH}^{-}$ions per droplet. For $[\mathrm{AOT}]=0.1 \mathrm{M}, w_{0}=12.5$, and taking an aggregation number of 145.5 (Table 3 ), values of $\alpha$ have been calculated for occupation of droplets by between 0 and 4 hydroxide ions and are shown in Figure 7. The $\mathrm{pH}$ is that of the solution added. It is clear that, up to $\mathrm{pH} 11$, the number of droplets containing hydroxide ions is very small. Further, for nonbuffered solutions, an overall $\mathrm{pH}$ of the microemulsion system does not have any clear meaning. For these solutions, assuming a droplet water radius of $2.84 \mathrm{~nm}$ (Table 3 ), the $\mathrm{pH}$ values for droplet with 1 , 2,3 , and 4 hydroxide ions are $12.2,12.5,12.7$, and 12.85, respectively. Thus, the observed effects of $\mathrm{pH}$ on the spectra and lifetimes and the observation of $\mathrm{C}$ at apparent $\mathrm{pH}$ values much higher than the $\mathrm{p} K_{\mathrm{a}}$ of harmine are best seen as the effects of distribution of hydroxide ions between the droplets on the ground state acid-base equilibria of harmine.

The lifetime of the cation is independent of " $\mathrm{pH}^{\circ}$, and its value ( $\tau_{3}=6.1 \pm 0.1 \mathrm{~ns}$ ) is close to that in pure water. However, from the amplitude data for cation $\left(a_{3}\right)$ at $350 \mathrm{~nm}$, where the dominant emission is from the neutral species, no increase is observed upon increasing $\mathrm{pH}$, showing that $\mathrm{C}^{*}$ decays with formation of $\mathrm{Z}^{*}$ at high $\mathrm{pH}$. If this involves reaction between $\mathrm{C}^{*}$ and the hydroxide ion, its efficiency will be limited by both the occupancy of $\mathrm{OH}^{-}$ions in the droplets and diffusion during the lifetime of $\mathrm{C}^{*}$. The root-mean-square distance of diffusion $\left\langle x^{2}\right\rangle^{1 / 2}$ is given by ${ }^{35}$

$$
\left\langle x^{2}\right\rangle^{1 / 2}=(2 D t)^{1 / 2}
$$

Taking a diffusion coefficient of $2.8 \times 10^{-5} \mathrm{~cm}^{2} \mathrm{~s}^{-1}$ for hydroxide in water under these conditions ${ }^{36}$ and a lifetime of 6 $\mathrm{ns}$ for $\mathrm{C}^{*}$ gives a value of $\left\langle x^{2}\right\rangle^{1 / 2}=1.8 \mathrm{~nm}$, which is rather smaller than the diameter of the droplets ( $\mathrm{ca} .5-6 \mathrm{~nm}$ ) under these conditions. Thus, during the lifetime of $\mathrm{C}^{*}$ there is less than a $50 \%$ chance that it will encounter a hydroxide ion. With the neutral species in the water-rich region, $\tau_{1}$ (lifetime of excited neutral in microemulsion droplets $\left(N^{*}{ }_{\mu \mathrm{E}}\right)$ ) shows a small, but significant, increase with apparent $\mathrm{pH}$ up to $\mathrm{pH} 12$. Above this value, it is not possible to kinetically distinguish between this and $\tau_{2}$ (lifetime of $\mathrm{N}^{*}$ in cyclohexane). However, at all $\mathrm{pH}$ values the lifetime of $\mathrm{N}^{*}$ in the microemulsion droplets $\left(\tau_{1}\right)$ is greater than that of the neutral species in pure water, which has a value of $0.48 \pm 0.03$ ns over the $\mathrm{pH}$ range $7-12 .{ }^{30}$ It is suggested, therefore, that $\tau_{1}$ corresponds to decay of the neutral species at the microemulsion interface. This result is in agreement with the spectral studies and follows from the low solubility of this species in water in the ground state. The longer lifetime compared with that of pure water is probably a result of differences in the structure of water at the droplet interface compared with bulk water, as has previously been shown by NMR, ${ }^{37}$ FTIR, ${ }^{38}$ and fluorescence probe ${ }^{39}$ studies. While the $\mathrm{pH}$ effects must be considered in terms of the distribution of $\mathrm{OH}^{-}$ions between droplets, the decrease in lifetime on decreasing $\mathrm{pH}$ may suggest that protonation of the neutral species at the interface is a significant reaction. Indicator studies in progress ${ }^{40}$ strongly suggest that there is a $\mathrm{pH}$ gradient both in these droplets and in AOT/water liquid crystals, possibly due to double-layer effects. From these results, even for systems whose bulk $\mathrm{pH}$ is close to neutrality, the $\mathrm{pH}$ at the interface may be considerably lower.

At $500 \mathrm{~nm}$, where the neutral species in water does not emit, a similar kinetic component to that at $350 \mathrm{~nm}$ is observed as a rise time, whose amplitude, which is negative (as this corresponds to a growing-in of emission), also increases with increasing $\mathrm{pH}$. The only probable candidates for this growingin are $\mathrm{Z}^{*}$ or $\mathrm{C}^{*}$. However, it is hard to see why the yield of $\mathrm{C}^{*}$ should increase with increasing $\mathrm{pH}$, and it is tempting to assign this process to the interconversion of $\mathrm{N}^{*}$ in this phase to $Z^{*}$. While this may not be the only possible assignment, some support for this comes from the effect of $\mathrm{pH}$ on the preexponential amplitude of the zwitterion $\left(a_{4}\right)$, as will be discussed in the next section.

Within experimental error, the lifetime of the neutral species in the cyclohexane phase $\left(\tau_{2}\right)$ is independent of the $\mathrm{pH}$ of the microemulsion droplets. However, its value $\left(\tau_{2}=3.2 \pm 0.2\right.$ ns) is shorter than that in the pure solvent. A possible explanation will be presented after consideration of the effect of $w_{0}$ on the photophysics of harmine in these systems. It is noted, in addition, that the amplitude of this component $\left(a_{2}\right)$ shows a significant increase with increasing $\mathrm{pH}$.

The lifetime of the zwitterion, $\tau_{4}$, is intermediate between the values for pure water $\left(14.1 \mathrm{~ns}^{30}\right)$ and for methanol $\left(28 \mathrm{~ns}^{18}\right)$, and it is suggested that this might correspond to this species being localized at the interface. Comparison of the lifetimes of $\mathrm{N}^{*}$ and $\mathrm{Z}^{*}\left(\tau_{1}\right.$ and $\tau_{4}$ ) with values for various dioxanewater mixtures ${ }^{41}$ suggests that these species are in a region with polarity close to that of $20 \%$ dioxane-water, compatible with harmine being predominantly in the zone of the AOT headgroup.

If the interpretation of the $\mathrm{pH}$ behavior of the neutral species $\mathrm{N}^{*}$ in the microemulsions is correct, and this correspond to interconversion of this species to the cation and zwitterion, the 
TABLE 4: Fluorescence Decay Times $\left(\tau_{i}\right)$ and Preexponential Factors $\left(a_{i}\right)$ for Decay of Harmine Fluorescence in $\mathrm{AOT} / \mathrm{H}_{2} \mathrm{O}$ / Cyclohexane Microemulsions $([\mathrm{AOT}]=0.1 \mathrm{M}, \mathrm{pH}=5.5)$ at $20^{\circ} \mathrm{C}$ as a Function of $\omega_{0}$

\begin{tabular}{|c|c|c|c|c|c|c|c|c|c|c|}
\hline$\omega_{0}$ & $\lambda_{\mathrm{em}} / \mathrm{nm}$ & $\tau_{1} / \mathrm{ns}$ & $\tau_{2} / \mathrm{ns}$ & $\tau_{3} / \mathrm{ns}$ & $\tau_{4} / \mathrm{ns}$ & $a_{1}$ & $a_{2}$ & $a_{3}$ & $a_{4}$ & $\chi^{2}$ \\
\hline \multirow[t]{3}{*}{2.5} & 350 & 1.6 & 4.3 & 6.0 & 19.4 & 0.070 & 0.91 & 0.021 & $5.9 \times 10^{-5}$ & 1.03 \\
\hline & 410 & & & 5.7 & 17.2 & & & 0.97 & 0.027 & 1.12 \\
\hline & 500 & 1.6 & & 6.0 & 19.4 & -0.25 & & 0.98 & 0.019 & 1.24 \\
\hline \multirow[t]{2}{*}{5} & 350 & 1.5 & 4.0 & 5.9 & 18.3 & 0.11 & 0.87 & 1.00 & & 1.14 \\
\hline & 500 & 1.5 & & 5.9 & 18.3 & -0.29 & & 0.96 & 0.044 & 1.13 \\
\hline \multirow[t]{3}{*}{7.5} & 350 & 1.2 & 3.6 & 6.2 & 20.5 & 0.14 & 0.83 & 0.027 & $99.5 \times 10^{-5}$ & 1.13 \\
\hline & 410 & & & 5.9 & & & & 1.00 & & 1.05 \\
\hline & 500 & 1.2 & & 6.2 & 20.5 & -0.27 & & 0.96 & 0.027 & 1.13 \\
\hline \multirow[t]{3}{*}{10} & 1.3 & 3.4 & 6.1 & 18.2 & 0.17 & 0.75 & 0.075 & 0.075 & $66.7 \times 10^{-5}$ & 1.48 \\
\hline & 410 & & & 6.0 & & & & 1.00 & & 1.12 \\
\hline & 500 & 1.6 & & 6.1 & 18.2 & -0.28 & & 0.97 & 0.033 & 1.17 \\
\hline \multirow[t]{3}{*}{12.5} & 350 & 1.3 & 3.2 & 6.1 & & 0.18 & 0.75 & 0.06 & & 1.11 \\
\hline & 410 & & & 6.0 & & & & 1.00 & & 1.08 \\
\hline & 500 & 1.4 & & 6.1 & 22.0 & -0.21 & & 0.98 & 0.01 & 1.27 \\
\hline \multirow[t]{3}{*}{15} & 350 & 1.4 & 3.2 & 6.4 & 26.1 & 0.28 & 0.68 & 0.041 & $100 \times 10^{-5}$ & 1.13 \\
\hline & 410 & & & 6.1 & & & & 1.00 & & 0.99 \\
\hline & 500 & 1.4 & & 6.4 & 26.1 & -0.17 & & 0.99 & 0.015 & 1.15 \\
\hline
\end{tabular}

decay of $\mathrm{N}^{*}{ }_{\mu \mathrm{E}}$ will be given by the processes

$$
\begin{gathered}
\mathrm{N}_{\mu \mathrm{E}}^{*} \stackrel{k_{\mathrm{f}}}{\rightarrow} \mathrm{N}+h v \\
\mathrm{~N}_{\mu \mathrm{E}}^{*}+\mathrm{H}^{+} \stackrel{k_{\mathrm{C}}}{\rightarrow} \mathrm{C}^{*} \\
\mathrm{~N}_{\mu \mathrm{E}}^{*}+\mathrm{H}_{2} \mathrm{O} \stackrel{k_{\mathrm{W}}}{\rightarrow} \mathrm{C}^{*}+\mathrm{OH}^{-} \\
\mathrm{N}_{\mu \mathrm{E}}^{*} \stackrel{k_{\mathrm{z}}}{\rightarrow} \mathrm{Z}^{*}
\end{gathered}
$$

In water, it is not possible to observe reaction 2 because the ground state $\mathrm{p} K_{\mathrm{a}}(\mathrm{C} / \mathrm{N})$ is lower than that of the excited state, such that at low $\mathrm{pH}$ values harmine will always be protonated while, because of the short lifetime of $\mathrm{N}^{*}$, at high $\mathrm{pH}$ reaction 3 will always be more important than reaction 2 . However, if, as suggested earlier, harmine in the microemulsion system is at the AOT/water interface, this is a region of low water activity and high hydrogen ion concentration such that reaction 2 is now an important process. From this scheme, we can make two important predictions. First, the rate constant for decay of $\mathrm{N}^{*}$ in the microemulsion droplets $\left(k_{1}=1 / \tau_{1}\right)$ should be a linear function of interfacial hydrogen ion concentration, and second, if the interconversion of $\mathrm{C}^{*}$ to $\mathrm{Z}^{*}$ is negligible (i.e., the effective $\mathrm{pH}$ is low), the quantum yield of zwitterion formation shuold be directly proportional to $\tau_{1}$, since

$$
\Phi_{\mathrm{Z}^{*}} \propto k_{\mathrm{z}} \tau_{1}
$$

Consideration of the interfacial hydrogen ion concentration requires knowledge of both hydroxide ion distribution between the droplets and any $\mathrm{pH}$ gradient at the interface. However, it is reasonable to assume that this is some function of the total hydrogen ion concentration of the aqueous subphase. Because of uncertainties inherent in separation of lifetimes and amplitudes for the various species for these multiexponential decays, caution is needed in discussing the kinetic data. However, it is satisfying to note with the data in Table 2 that, on increasing bulk $\mathrm{pH}$, increases are observed in both $\tau_{1}$ and the amplitude $a_{4}$ for the zwitterion emission at $500 \mathrm{~nm}$ (which can be taken as a measure of the quantum yield for $\mathrm{Z}^{*}$ formation), supporting the above general scheme.

The radius of the water pool for AOT microemulsions is directly proportional to the water/surfactant mole ratio $\left.\left(w_{0}\right)\right)^{42.43}$ The decay of excited harmine was studied at constant $\mathrm{pH}$ (5.5) in the microemulsions over the range $2.5 \leq w_{0} \leq 15$. Kinetic

analysis showed the presence of four kinetically distinguishable species over the whole range (Table 4).

The lifetimes of the neutral species in the microemulsion droplets $\left(\tau_{1}=1.45 \pm 0.14 \mathrm{~ns}\right)$, the cation $\left(\tau_{3}=6.1 \pm 0.2 \mathrm{~ns}\right)$, and the zwitterion ( $\tau_{4}=20.2 \pm 3.1 \mathrm{~ns}$ ) appear to be effectively independent of $w_{0}$. However, the lifetime of the neutral species in cyclohexane $\left(\tau_{2}\right)$ decreases with increasing $w_{0}$. Further, up to $w_{0}=12.5,1 / \tau_{2}$ is a linear function of $w_{0}$ (correlation coefficient $r=0.996$ ). Extrapolation to $w_{0}=0$ gives a lifetime $(4.75 \mathrm{~ns})$ which is close to that of the neutral species in pure cyclohexane. A possible explanation is that the neutral species in cyclohexane is effectively quenched by the microemulsion droplet in the process

$$
\mathrm{N}_{\mathrm{CX}}^{*}+\mu \mathrm{E} \stackrel{k_{\mathrm{q}}}{\rightarrow} \mathrm{N}_{\mu \mathrm{E}}^{*}
$$

Since the lifetime of the excited neutral species in microemulsion droplets is less than that in cyclohexane, this process becomes rate determining. Using literature data for AOT microemulsion aggregation numbers (number of monomers of AOT per microemulsion aggregate) in cyclohexane, ${ }^{42,43}$ the second-order rate constant for this process has been calculated for the various $w_{0}$ values (Table 3 ). The rates calculated for this process are high and are likely to be dominated by diffusion. For diffusioncontrolled process, the rate constant is given by the Smoluchowski equation ${ }^{44} k_{\text {diff }}=4 \pi \sigma_{\mathrm{A}} D N$, where $\sigma_{\mathrm{A}}$ is the particle radius and $D$ the diffusion coefficient. If reaction 5 is diffusion controlled, a plot of $k_{\mathrm{q}}$ against the microemulsion droplet radius should be linear. Using data from Table 3 , a reasonable linear relationship is observed (Figure 8). Further, from the slope of this graph it is possible to estimate a diffusion coefficient $D=$ $1.5 \times 10^{-4} \mathrm{~cm}^{2} \mathrm{~s}^{-1}$ for cyclohexane solution. Diffusion coefficients can also be calculated from solvent viscosity $(\eta)$ using the Stokes-Einstein relationship, ${ }^{34} D=k T / 6 \pi \eta \sigma_{\mathrm{A}}$. Because harmine is much smaller than the microemulsion droplets, we can assume, as a first approximation, that this is the main diffusing species. Using a typical value $\sigma_{\mathrm{a}}=5 \AA$, gives a diffusion coefficient $4.2 \times 10^{-4} \mathrm{~cm}^{2} \mathrm{~s}^{-1}$ for cyclohexane solutions at $20^{\circ} \mathrm{C}$. Given the somewhat drastic approximations involved in these calculations, the order of magnitude agreement is encouraging and supports the basic suggestion that the decrease in the lifetime of the neutral species in the cyclohexane phase with increasing $w_{0}$ is associated with diffusion of $\mathrm{N}^{*} \mathrm{cx}$ to the microemulsion droplets.

Partitioning of Harmine between Cyclohexane and Microemulsion Droplets. Considering the preexponential amplitudes of the various components in Table 4 , the values 


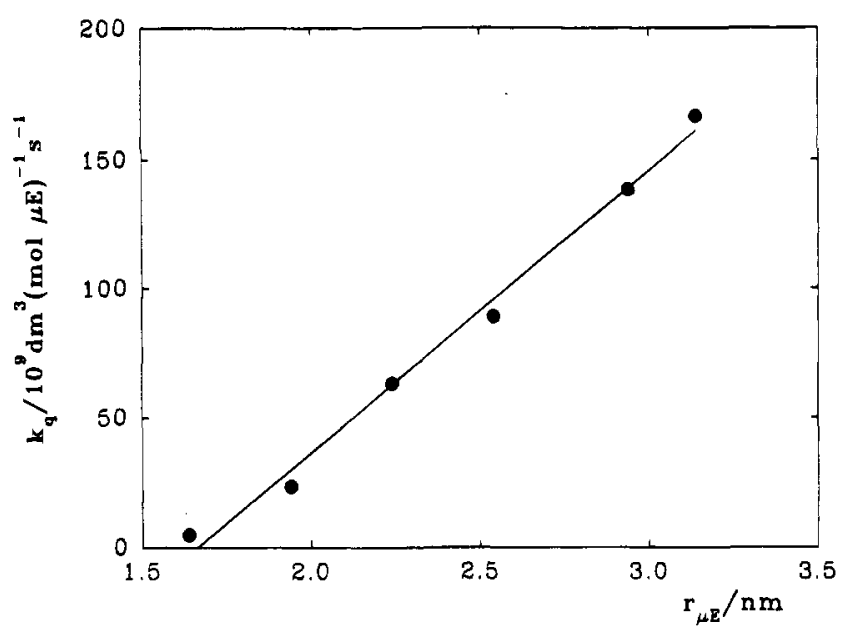

Figure 8. Plot of quenching of excited neutral form of harmine in cyclohexane phase as a function of radius of microemulsion droplets.

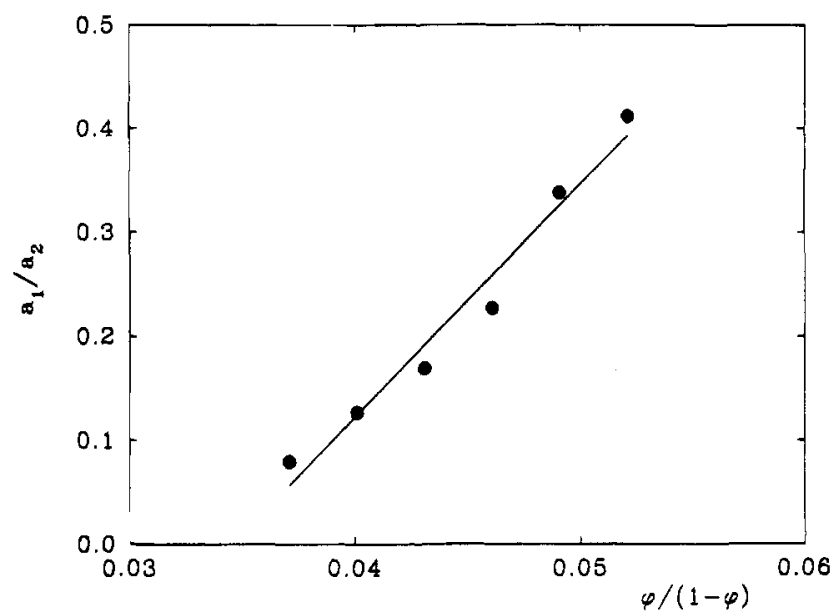

Figure 9. Plot of amplitudes of neutral form of excited harmine in microemulsion and cyclohexane phases as a function of their volume ratio.

obtained at $350 \mathrm{~nm}$ for $a_{1}$ are seen to increase and for $a_{2}$ to decrease on increasing $w_{0}$. A likely explanation is that we are getting partitioning of the neutral species between cyclohexane and the microemulsion droplets. If this is due to partitioning in the ground state (i.e., before excitation), the amplitudes should be proportional to the product of the number of the molecules in each phase $\left(n_{i}\right)$ and the extinction coefficient $\left(\epsilon_{i}\right)$ in that phase at the excitation wavelength $\left(a_{i} \propto n_{i} \epsilon_{i}\right)$. We can define a distribution coefficient

$$
K=\frac{[\mathrm{Hi}]_{\mathrm{Cx}}}{[\mathrm{Hi}]_{\mu \mathrm{E}}}=\frac{n_{\mathrm{Cx}}}{(1-\varphi) V} \frac{\varphi V}{n_{\mu \mathrm{E}}}
$$

where $n_{\mathrm{cx}}$ and $\mathrm{n}_{\mu \mathrm{E}}$ are the number of molecules in each phase, $\varphi$ is the volume fraction of the microemulsion droplets, and $V$ is the molar volume of the solution. We can thus suggest that a plot of the relationship of the amplitudes in microemulsion droplet and bulk cyclohexane phases against the volume fraction ratio shuold be linear. Although uncertainties are inherent in the values of $a_{1}$ and $a_{2}$ as a result of the separation of multiexponential decays, the experimental data can be fitted to straight line (Figure 9). From the slope and the values of the extinction coefficients at the excitation wavelength of $337 \mathrm{~nm}$ $\left(\epsilon_{\mathrm{C}^{*}}-1.07 \times 10^{4} \mathrm{M}^{-1} \mathrm{~cm}^{-1}, \epsilon_{\mathrm{N}^{*}}(\right.$ water $)=5.05 \times 10^{3} \mathrm{M}^{-1}$ $\mathrm{cm}^{-1}, \epsilon_{\mathrm{N}}^{*}($ cyclohexane $)=1.82 \times 10^{3} \mathrm{M}^{-1} \mathrm{~cm}^{-1}$ ), a value of $K$ $=0.12 \pm 0.02$ was estimated. Even considering the approximations involved in this analysis, the results clearly show
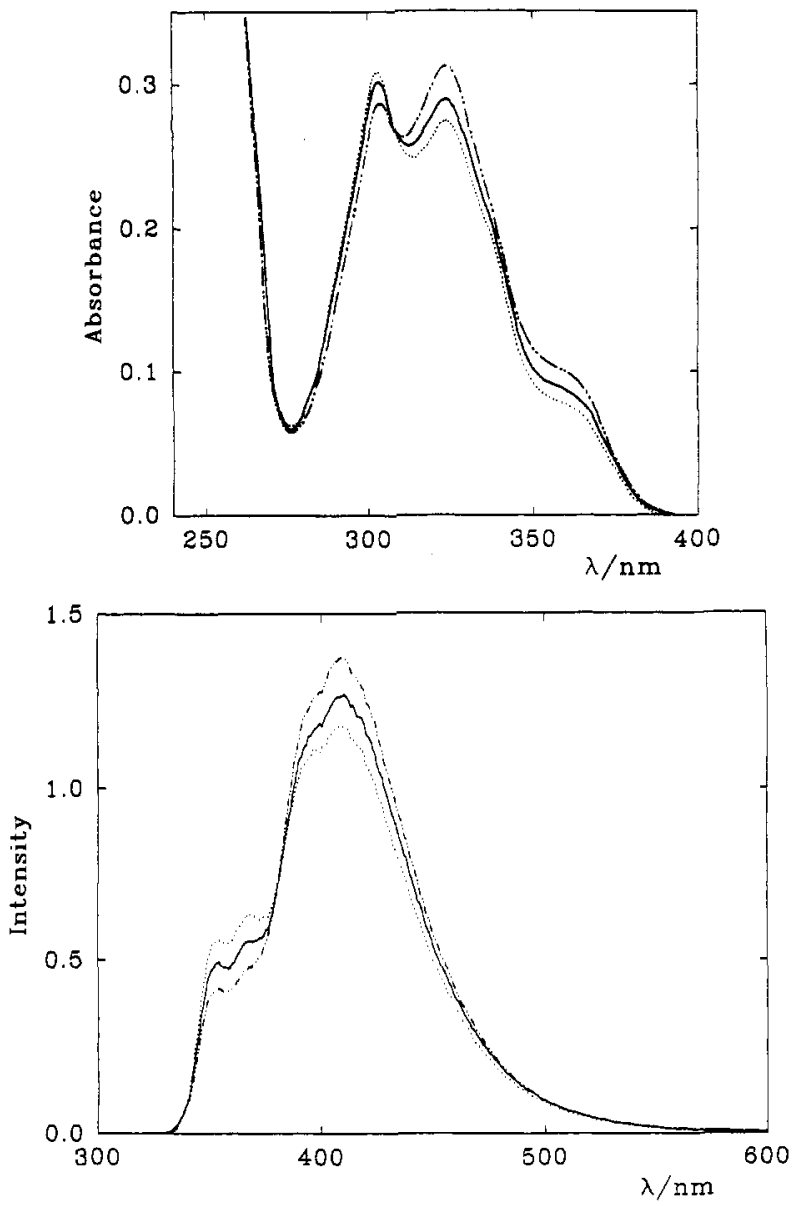

Figure 10. Changes in (a, top) absorption spectra and ( $b$, bottom) emission spectra of harmine in AOT/water/cyclohexane microemulsions $\left([\mathrm{AOT}]=0.1 \mathrm{M}, w_{0}=5, \mathrm{pH}=5.5\right)$ upon addition of methanol: without methanol (-..-), $0.074 \mathrm{M}$ methanol $(-)$, and $0.098 \mathrm{M}$ methanol (*).

a partition coefficient much lower than that between octanol and water under similar conditions and show a higher concentration in the microemulsion droplet than expected just from partitioning between cyclohexane and water. The results support a model in which the neutral form of harmine partitions between cyclohexane and the AOT/water interface, while the cation is predominantly in the aqueous phase.

Effect of Polarity on Acid-Base Behavior in Microemulsions. From the above results, a general picture emerges, where the neutral $\beta$-carbolines in their ground states are distributed between the cyclohexane phase, and the interfacial region between surfactant and water, while the cation is predominantly in a water-rich region. Upon excitation, changes in the distribution of the neutral species may be occurring, due to differences in electron density, and the results suggest that partitioning can occur during the lifetimes of the excited singlet states. While excited state partitioning has been observed for singlet oxygen in microemulsion systems, ${ }^{45}$ we are not aware of other examples of partitioning of excited species with such short lifetimes as these. Both distribution studies on octanolwater systems and photophysical studies in the microemulsions suggest that there is partitioning between cation in the aqueous subphase and neutral and/or zwitterion in the interfacial region. Further, addition of methanol to the microemulsion system, which from both octanol-water partition coefficients ${ }^{46}$ and extrapolation of partitioning data for short chain length alcohols between water and phospholipid membranes ${ }^{47}$ is expected to be predominantly in the aqueous phase, will be expected to reduce the polarity of the water pool and push the above 
equilibria in the direction of neutral/zwitterion. As can be seen in Figure 10, this prediction is verified experimentally from changes in both absorption and fluorescence spectra observed upon addition of methanol to the system AOT/water/cyclohexane $([\mathrm{AOT}]=0.1 \mathrm{M}, \mathrm{pH}=5.5)$. Good isosbestic points are observed for changes in both absorption and fluorescence spectra, suggesting that we are just seeing the effect of changing polarity on a simple equilibra between $C$ and $N / Z$ in both ground and excited states.

Acknowledgment. We are greatly indebted to a referee for his valid criticisms, in particular concerning the compartmentalization of hydroxide ions between the microemulsion droplets. A.L.M. thanks the Alexander von Humbolt Foundation, Drs. K. Zachariase and R. Busse for their support for the construction of the single-photon-counting equipment, and G. Striker for making his deconvolution program available. Financial support from the Junta Nacional de Investigação Cientifica (JNICT, Grants STRD/C/AMB/40/92 and BD/1680/91-IF) is gratefully acknowledged.

\section{References and Notes}

(1) Allen, J. R. F.; Holmstedt, B. R. Phytochemistry 1980, 19, 1573.

(2) McKenna, D. J.; Towers, G. H. N. Phytochemistry 1981, 20, 1001.

(3) Arnason, T.; Towers, G. H. N.; Philogene, B. J. R.; Lambert, J. D. H. In Plant Resistance to Insects; Hedin, P., Ed.; ACS Symposium Series No. 330; American Chemical Society: Washington, DC, 1981; pp 139151.

(4) Towers, G. H. N.; Abramowski, Z. J. Nat. Prod. 1983, 46, 576. (5) Hudson, J. B. E. A.; Graham, R.; Fong, L. L.; Towers, G. H. N. Photochem. Photobiol. 1986, 44, 483.

(6) (a) Towers, G. H. N.; Hudson, J. B. Photochem. Photobiol. 1987, 46, 61. (b) Tuveson, R. W. In Light-Activated Pesticides; Heitz, J. R., Downum,K. R., Eds.: ACS Symposium Series No. 339; American Chemical Society: Washington, DC, 1987: pp 192-205. (c) Larson, R. A.; Marley, K. A.; Tuveson, R. W.; Berenbaum, M. R. Photochem. Photobiol. 1988, 48,665 .

(7) Dillon, J.; Spector, A.; Makaniski, K. Nature 1976, 259, 422.

(8) Zigler, J. S.; Gossey, J. P. Photochem. Photobiol. 1981, 33, 869.

(9) Sen, A. C.; Ueno, N.; Chakrabasti, B. Photochem. Photobiol. 1992, 55,753 .

(10) Ghiggino, K. P.; Skilton, P. F.; Thistlethwaite, P. J. J. Photochem. 1985,31

(11) Pardo, A.; Reyman, D.; Poyato, J. M. L.; Medina, F. J. Lumin. 1982, 42, 163. 171 .

(12) Wolfbeis, O. S.; Furlinger, E. Z. Phys. Chem. (Munich) 1982, 129

(13) Wolfbeis, O. S.; Furlinger, E.; Wintersteiger, R. Monatsh. Chem. 1982, 113, 509. Wolfbeis, O. S.; Furlinger, E. Ibid. 1982, 113, 529.

(14) Sakurovs, R.; Ghiggino, K. P. J. Photochem. 1982. 18, 1.

(15) Vert, F. T.; Sanchez, I. Z.; Torrent, A. O. J. Photochem. 1983, 23 , 355.

(16) Pardo, A.; Reyman, D.; Martins, E.; Poyato, J. M. L.; Camacho, J. J. J. Lumin. 1988, 42, 163.
(17) Olba, A.; Thomas, F.; Zabala, I. J. Lumin. 1990, 47, 27.

(18) Dias, A.; Varela, A. P.; Miguel, M. G.; Maçanita, A. L.; Becker, R. S. J. Phys. Chem. 1992, 96, 10290. Varela, A. P.; Dias, A.; Miguel, M G.; Becker, R. S.; Maçanita, A. L. J. Phys. Chem. 1995, 99, 2239.

(19) Balon, M.; Hidalgo, J.; Guardado, P.; Muñoz, M. A.; Carmona, C. J. Chem. Soc., Perkin Trans. 2 1993, 99.

(20) Draxler, S.; Liffitsch, M. E. J. Phys. Chem. 1993, 97, 11493; 1995, 99,2241

(21) Munier, R. L.; Meunier, S. Chromatographie 1980, 13, 259.

(22) Biagi, G. L.; Pietrogrande, M. C.; Barbaro, A. M.; Guerra, M. C.; Borea, P. A.; Cantelli Forti, G. J. Chromatogr. 1989, 469, 121.

(23) Perrin, D. D.; Armarego, W. L. F.; Perrin, D. R. In Purification of Laboratory Chemicals; Pergamon Press: New York, 1980.

(24) Wong, M.; Thomas, J. K.; Gratzel, M. J. Am. Chem. Soc. 1976, 98,2391

(25) Eastoe, J.; Fragneto, G.; Robinson, B. H. J. Chem. Soc., Faraday Trans. 1992, 88, 461. 3783.

(27) Maçanita, A. L.; Costa, F. P.; Costa, S. M. B.; Melo, E. C.; Santos, H. J. Phys. Chem. 1989, 93, 336.

(28) Zachariasse, K.; Duveneck, G.; Busse, R. J. Am. Chem. Soc. 1984, 106, 1045.

(29) Striker, G. In Deconvolution and Reconvolution of Analytical Signals; Bouchy, M., Ed.; University Press: Nancy, France, 1982; p 329.

(30) Dias, A.; Varela, A. P.; Miguel, M. G.; Maçanita, A. L.; Becker. R. S., to be submitted.

(31) Luisi, P. L.; Giomini, M.; Pileni, M. P.; Robinson, B. H. Biochim. Biophys. Acta 1988, 947, 209.

(32) Infelta, P. P.; Grätzel, M. J. Chem. Phys. 1979, 70, 179.

(33) Infelta. P. P. Chem. Phys. Lett. 1979, 61, 88.

(34) Jóhannsson, R.; Almgren, M. Langmuir 1993, 9, 2879 and references therein.

(35) Atkins, P. W. Physical Chemistry, 5th ed.; Oxford University Press: Oxford, 1994; pp 850, 854

(36) Lobo, V. M. M. Handbook of Electrolyte Solutions: Part A; Elsevier: Amsterdam, 1989; pp 1085-1086.

(37) MacDonald, H.; Bedwell, B.; Gulari, E. Langmuir 1986, 2, 704. (38) Seanatra, D.; Lendinara, L.; Giri, L. G. Can. J. Phys. 1990, 68, 1041

(39) Hasegawa, M.; Sugimura, T.; Suzaki, Y.; Shindo, Y.; Kitahara, A. J. Phys. Chem. 1994, 98, 2120

(40) Burrows, H. D.; Varela, A. P.; Miguel, M. G., unpublished observations.

(41) Dias, A.; Varela, Al. P.: Miguel, M. G.; Maçanita, A. L.; Becker, R. S. Manuscript in preparation.

(42) Day, R. A.; Robinson, B. H.; Clarke, J. H. R.; Doherty, J. V. $J$. Chem. Soc., Faraday Trans. 1 1979, 75, 132.

(43) Izquierdo, C.; Moyá, M. L.; Usero, J. L.; Casado, J. Monatsch. Chem. 1992, 123, 383

(44) Smoluchowski, M. Z. Phys. Chem. (Munich) 1917, 92, 129.

(45) Lee, P. C.; Rodgers, M. A. J. J. Phys. Chem. 1983, 87, 4894.

(46) Leo, A.; Hansch, C.; Elkins, D. Chem. Rev. 1971, 71, 525. Leo, A. J. Chem. Rev. 1993, 93, 1281.

(47) Kamaya, H.; Kaneshina, S.; Ueda, I. Biochim. Biophys. Acta 1981, $646,135$.

JP951857Z 